\title{
Drug Dose Adjustments in Chronic Kidney Disease Patients
}

\section{Roja Rani K*, Prasanth Munaswamy and Susmitha Bhaskar Yerramasetty}

Pharm D, Department of Pharmacy Practice, Sri Padmavathi School of Pharmacy, Tirupathi, Andhra Pradesh, India

*Corresponding Author: Roja Rani K, Pharm D, Department of Pharmacy Practice, Sri Padmavathi School of Pharmacy, Tirupathi, Andhra Pradesh, India.
Received: August 08, 2020

Published: September 28, 2020

(C) All rights are reserved by Roja Rani K. et al.

\section{Abstract}

The incidence of Chronic Kidney Disease are extremely increasing world wide due to rise in diabetes, hypertension, cardiova scular diseases. As kidney is a main eliminating organ, its function decreases in renal failure results in build up of drugs which cause toxic effects. The aim is to assess the prescribing drug dose adjustment in chronic kidney disease patients. Objectives are to predict glomerular filtration rate by using Modified diet in renal failure formulae. To assess the drug dose adjustments in renal failure patients. A prospective observational study was carried out in SVRRGGH during October 2016 to March 2017. A total of 125 patients diagnosed with CKD are included in study. Patients who are not willing, below 18 years, special population including pregnant, lactating women were excluded from study. Proforma was used to collect data. Total of 125 patients were included in study, men constituted $86(68.8 \%)$ of total population. Most effected age group was 51 - 60 years (29.6\%). The study population with stage-4, 44 (35.2\%) were higher. In total 1163 studied drugs, only 149 drugs are to be dose adjusted, out of that 102 (68.45\%) were not dose adjusted and 47 (31.54\%) were adjusted. It is concluded that more than half of drugs was not dose adjusted and there is need of dose adjustment in hospitalized chronic kidney disease patients. Continuous medical education of physicians and collaboration with clinical pharmacist is an important issue for quality improvement regarding renally impaired patients.

Keywords: Chronic Kidney Disease; Dose Adjustments; Renal Failure; Glomerular Filtration Rate

\section{Abbreviations}

CKD: Chronic Kidney Disease; GFR: Glomerular Filtration Rate; K/ DOQI: Kidney Disease Outcomes Quality Initiative; MDRD: Modified of Diet in Renal Disease; NKF: National Kidney Foundation; SVRRGGH: Sri Venkateswara Ramnarayan Ruia Government General Hospital

\section{Introduction}

The Kidney Disease Outcomes Quality Initiative (K/DOQI) of the National Kidney Foundation (NKF) defines CKD as either kidney damage or a decreased glomerular filtration rate of less than $60 \mathrm{~mL} / \mathrm{min} / 1.73 \mathrm{~m}^{2}$ for 3 or more months [1]. Chronic Kidney Disease is a world wide public health problem with an increasing prevalence, incidence, poor outcomes and high cost [2]. Chronic kidney disease decreases kidney function, resulting in decrease in elimination of drugs which leads to accumulation of drugs and precipitation of adverse drug reaction [2]. CKD affects the elimination of renally excreted drugs and other pharmacokinetic processes involved in drug disposition [2]. In renal failure patients dosing errors can cause adverse effects and poor outcomes. Dose of drugs should be adjusted according to creatinine clearance or GFR [2]. Inappropriate dosing in patients with chronic kidney disease can cause in effective therapy. In particular, older patients are at high risk of developing adverse events caused by age related decline in reneal function and the use of multiple medications to treat comorbid conditions [2]. Recommended equations for estimation 
of glomerular filtration rate (GFR) using serum creatinine concentration $\left(\mathrm{S}_{\mathrm{Cr}}\right)$, age, sex, race, and bodyweight.

Equation from the modification of diet in renal disease study (MDRD): Estimated GFR (mL/min per $\left.1.73 \mathrm{~m}^{2}\right)=186 \mathrm{x}\left(\mathrm{S}_{\mathrm{Cr}}\right)^{-1.154} \mathrm{x}$ (age $)^{-0.203} \times(0.742$ for women).

Cockcroft-Gault equation: Estimated creatinine clearance (mL/ $\min )$.

(140-age) x body weight $(\mathrm{kg})$

$72 \times \mathrm{S}_{\mathrm{Cr}}(\mathrm{mg} / \mathrm{dL})$

Multiply by 0.85 for women [3].

In this study MDRD equation was considered due to lack of information on body weight of patients.

\section{Aim of the Study}

To assess the prescribing drug dose adjustments in chronic kidney disease patients.

\section{Objectives of the Study}

- $\quad$ To predict the GFR by using Modified diet in renal failure formulae.

- $\quad$ Toassess the drug dose adjustments in renal failure patients.

\section{Methodology}

Study design: Prospective Observational study.

Study place: Sri Venkateswara Ramnarayan Ruia Government General Hospital (SVRRGGH).

Study duration: 6 months (October 2016 to March 2017).

Study size: 125 prescriptions.

Study site: Department of General Medicine.

Statistical analysis: Mean, Percentages.

\section{Inclusion criteria}

All inpatients with diagnosis of CKD in general medicine department both male and female medical wards.

\section{Exclusion criteria}

- Patients below 18 years

- Patients who were not willing.

- $\quad$ Special population including pregnant women and lactating women.

\section{Data collection}

A designed proforma and informed consent form was used for collection of data. The proforma contain patient demographics, diagnosis, admission complaints, past medical history, past medication history, family and surgical history, laboratory investigation reports and drugs prescribed. A evaluation proforma was used to evaluate data from proforma. Evaluation proforma contain information on co-morbidities, risk factors in CKD patients, estimation of GFR, CKD stage and dosage adjustment of drugs.

By using Modified Diet in Renal Disease (MDRD) formula Glomerular Filtration Rate (GFR) was estimated. Stage of CKD can classified based GFR value. A specially designed dose adjustment guidelines was prepared by using Myrnay. Munar, Harleen Singh. American family physician guidelines [4] and used for dose adjustments of drugs in prescriptions. The doses of drugs are adjusted based on GFR. The data was collected manually and then entered to Excel sheet data base.

\section{Ethical consideration}

Study was carried out from October 2016 to March 2017 after obtaining permission from the Institutional Ethics Committee and after getting consent from all the participating subjects.

\section{Results}

\begin{tabular}{|l|c|c|}
\hline Gender & No. of Patients $(\mathbf{n = 1 2 5})$ & Percentage (\%) \\
\hline Male & 86 & $68.8 \%$ \\
\hline Female & 39 & $31.2 \%$ \\
\hline
\end{tabular}

Table 1: Gender wise distribution in the study population.

\begin{tabular}{|l|c|c|c|c|}
\hline $\begin{array}{l}\text { Age } \\
\text { (Years) }\end{array}$ & $\begin{array}{c}\text { Female } \\
\text { (n= 39) }\end{array}$ & $\begin{array}{c}\text { Male } \\
\text { (n= 86) }\end{array}$ & $\begin{array}{c}\text { Total } \\
\text { (n= 125) }\end{array}$ & $\begin{array}{c}\text { Percentage } \\
\text { (\%) }\end{array}$ \\
\hline $21-30$ & 1 & 3 & 4 & $3.2 \%$ \\
$31-40$ & 7 & 4 & 11 & $8.8 \%$ \\
$41-50$ & 8 & 18 & 26 & $20.8 \%$ \\
$51-60$ & 12 & 25 & 37 & $29.6 \%$ \\
$61-70$ & 4 & 27 & 31 & $24.8 \%$ \\
$71-80$ & 7 & 8 & 15 & $12 \%$ \\
$81-90$ & 0 & 1 & 1 & $0.8 \%$ \\
\hline
\end{tabular}

Table 2: Age distribution in study population. 


\begin{tabular}{|l|c|c|}
\hline CKD stage & No. of patients (n = 125) & Percentage (\%) \\
\hline Stage-1 & 5 & $4 \%$ \\
Stage-2 & 9 & $7.2 \%$ \\
Stage-3a & 13 & $10.4 \%$ \\
Stage-3b & 7 & $5.6 \%$ \\
Stage-4 & 44 & $35.2 \%$ \\
Stage-5 & 43 & $34.4 \%$ \\
None & 4 & $3.2 \%$ \\
\hline
\end{tabular}

Table 3: Stages of CKD in study population.

Stage 1: Kidney damage with normal or increased GFR ( $>90 \mathrm{~mL} /$ $\min / 1.73 \mathrm{~m}^{2}$ )

Stage 2: Mild reduction in GFR (60-89 mL/min/1.73 $\left.\mathrm{m}^{2}\right)$

Stage 3a: Moderate reduction in GFR ( $45-59 \mathrm{~mL} / \mathrm{min} / 1.73 \mathrm{~m}^{2}$ )

Stage 3b: Moderate reduction in GFR (30-44 mL/min/1.73 $\mathrm{m}^{2}$ )

Stage 4: Severe reduction in GFR $\left(15-29 \mathrm{~mL} / \mathrm{min} / 1.73 \mathrm{~m}^{2}\right)$

Stage 5: Kidney failure (GFR $<15 \mathrm{~mL} / \mathrm{min} / 1.73 \mathrm{~m}^{2}$ or dialysis)

None: Patients who are not undergone serum creatinine test.

\begin{tabular}{|c|c|c|c|}
\hline Drugs & Total & Adjusted & $\begin{array}{c}\text { Non } \\
\text { adjusted }\end{array}$ \\
\hline \multicolumn{4}{|l|}{ Anti hypertensives } \\
\hline Enalapril & 13 & 3 & 10 \\
\hline Atenolol & 4 & 1 & 3 \\
\hline Clonidine & 3 & 2 & 1 \\
\hline Spironolactone & 18 & 9 & 9 \\
\hline \multicolumn{4}{|l|}{ Cardiac glycosides } \\
\hline Digoxin & 8 & 1 & 7 \\
\hline \multicolumn{4}{|l|}{ Antiplatelets } \\
\hline Aspirin & 33 & 12 & 21 \\
\hline \multicolumn{4}{|l|}{ Antifungals } \\
\hline Fluconazole & 3 & 3 & 0 \\
\hline \multicolumn{4}{|l|}{ Antibiotics } \\
\hline Cefixime & 1 & 0 & 1 \\
\hline Cefoperazone and Sulbactam & 1 & 0 & 1 \\
\hline Cefotaxime & 1 & 0 & 1 \\
\hline Amoxicillin/Clavulanate & 15 & 2 & 13 \\
\hline Meropenem & 1 & 1 & 0 \\
\hline Piperacillin/tazobactam & 6 & 0 & 6 \\
\hline Norfloxacin & 2 & 1 & 1 \\
\hline Azithromycin & 4 & 0 & 4 \\
\hline Ciprofloxacin & 7 & 0 & 7 \\
\hline $\begin{array}{l}\text { Sulfamethoxazole+ } \\
\text { Trimethoprim }\end{array}$ & 3 & 2 & 1 \\
\hline \multicolumn{4}{|l|}{ Antacids } \\
\hline
\end{tabular}

\begin{tabular}{|l|c|c|c|}
\hline Ranitidine & 7 & 2 & 5 \\
\hline Anagesics & 6 & 4 & 2 \\
\hline Tramadol & 8 & 1 & 7 \\
\hline Antidiabetics & 5 & 3 & 2 \\
\hline Metformin & 149 & 47 & 102 \\
Glimepiride & & $(31.54 \%)$ & $(68.45 \%)$ \\
\hline Total (Percentage)
\end{tabular}

Table 4: Drug dosage adjustments in CKD patients.

\section{Discussion}

In this study only drugs need to be dose adjusted in renal failure was considered. Out of 1163 drugs 141 drugs need dose adjustment. Among the 149 drugs 102 (68.45\%) were nonadjusted and 47 (31.54\%) were adjusted. Were as in Abdulrahaman M Alahdal, Ahmed A: Elberry study [5] 53.1\% drugs are nonadjusted. In Ahsan Saleem, Imran Masood study [6] 58.2\% are unadjustded and 41.8\% are adjustded. The present study shows most drugs requiring dose adjustments was antibiotics especially Amoxicillin/Clavulanate. But in Abdulrahaman M Alahdal, Ahmed A: Elberry study [5] most dose adjustment needed drug is Vancomycin among antibiotics. The dose adjustment can done by reducing the dose of drug or by increasing the dosing interval. Followed by Amoxicillin/Clavulanate, Ciprofloxacin and Piperacillin/tazobactam are antibiotics need dose adjustment.

After antibiotics antihypertensives are drugs needed dose adjustment, especially Spironolactone 9, Enalapril 10 and Atenolol 3. Digoxin is a cardiac glycoside which has narrow therapeutic range (0.8 - 2 mcg per liter), above this level can cause serious toxicity. Higher or lower potassium levels may also lead to toxicity. Digoxin is mostly excreted in unchanged form by kidneys, in normal patients the half life of digoxin is 36 hours, in renal failure patients the elimination is much longer depending on stage of renal dysfunction. Hence in CKD dose adjustment of digoxin is important. In this study digoxin was given to 8 patients among them adjusted are one and unadjusted are seven, so most of patients needed dose adjust- ments. Even though Oral hypoglycemics are less prescribed due to their complications in CKD. Among prescribed drugs some needed dose adjustments.

Metformin was given to 8 patients in that one is adjusted and seven unadjusted. According to FDA metformin should not be used with decreased creatinine clearance or $\geq 1.4 \mathrm{mg} / \mathrm{dl}$ in women and serum creatinine $\geq 1.5 \mathrm{mg} / \mathrm{dl}$ in men. Because Metformin is renally cleared and may cause lactic acidosis in renal impairment. Glimepiride was prescribed to five patients among them only 2 patients need dose adjustment. Glimepiride and their metabolites are 
renally eliminated, leading to increased risk of hypoglycemia as GFR declines. Hence dose adjustments practice in the hospital has to be improved [7-10].

\section{Conclusion}

It is concluded that more than half of drugs was not dose adjusted, there is need of dose adjustment in hospitalized chronic kidney disease patients. Continuous medical education of physicians and collaboration with clinical pharmacist is an important issue for quality improvement regarding renally impaired patients.

\section{Bibliography}

1. 1.National Kidney Foudation. "KDOQI clinical practice guidelines for chronic kidney disease: Evaluation, classification, and stratification". American Journal of Kidney Diseases 39(2002):S1-266.

2. Sarah R Tomasello. “Chronic Kidney Disease”. Richard A. Helms, David J. Quan, Eric T. Herfindal, Dick R.Gourley. Text book of therapeutics drug and disease management. 8th edition. Unit- ed States of America: Lippincott Williams and Wilkins (2006): 1142-1175.

3. Joanne M Bargman and Karl Skoreck. Chronic kidney dis- ease. Anthony S.Fauci, Dennis L.Kasper,Dan L. Longo, Eugene Braunwald, Stephen L.Hauser, J. LarryJameson, Joseph Loscal- zc. Harrisons Principles of internal medicine. 17th edition. New York: Mcgraw-hill (2008): 1762.

4. Myrnay Munar and Harleen Singh. "Drug dosing adjustments in patients with chronic kidney disease". American Family Physician 75 (2007): 1487-1496.

5. Abdulrahman M Alahdal and Ahmed A. "Evaluation of apply- ing drug dose adjustment by physicians in patients with renal impairment". Saudi Pharmaceutical Journal 20 (2012): 217- 220.

6. Ahsan Saleem and Imran Masood. "Pattern and predictors of medication dosing errors in chronic kidney disease patients in Pakisthan: A single center retropective analysis". Plos One (2016).

7. Yahaya H., et al. "Drug use and dosing in chronic kidney dis- ease". Annals Academy of Medicine Singapore 38.12 (2009): 1095-1103.

8. Kappel J and Calissi P. “Nephrology: Safe drug prescribing for patients with renal insufficiency”. Canadian Medical Association Journal 166.4 (2002): 473-477.

9. Hudson JQ and Nyman HA. "Use of estimated glomerular rate rate for drug dosing in chronic kidney disease patient". Current Opinion in Nephrology and Hypertension 20.5 (2011): 482-491.

10. Van Dijk Ea., et al. "Drug dosage adjustments according to re-nal function at hospital discharge". Annals of Pharmacotherapy 40.7 (2006): 1254-1260. 


\section{Assets from publication with us}

- Prompt Acknowledgement after receiving the article

- Thorough Double blinded peer review

- Rapid Publication

- Issue of Publication Certificate

- High visibility of your Published work

Website: www.actascientific.com/

Submit Article: www.actascientific.com/submission.php

Email us: editor@actascientific.com

Contact us: +919182824667 